\title{
1 Wild pigs mediate far-reaching agricultural impacts 2 on tropical forest soil microbial communities
}

3

4 Francis Q. Brearley ${ }^{1 *}$, Hokyung Song ${ }^{2,3,4}$, Binu M. Tripathi ${ }^{4}$, Ke Dong ${ }^{5}$, Noraziah Mohamad Zin ${ }^{6}$, Abdul Rahim Abdul Rachman ${ }^{6,7}$, Kalan Ickes ${ }^{8}$, Jonathan M. Adams $^{9} *$ \& Matthew S. Luskin ${ }^{10,11,12 *}$

1) Department of Natural Sciences, Manchester Metropolitan University, Chester Street, Manchester, M1 5GD, UK

2) Department of Earth and Environmental Sciences, The University of Manchester, Manchester, M13 9PL, UK

3) Department of Biological Sciences, Seoul National University, Gwanak-ro1, Seoul, 08826, South Korea

4) Korea Polar Research Institute, Incheon, 21990, South Korea

5) Department of Life Sciences, Kyonggi University, Suwon, 16227, South Korea

6) Programme of Biomedical Science, Faculty of Health Sciences, Universiti Kebangsaan Malaysia, Kuala Lumpur, Malaysia

7) Present address: Faculty of Science, Technology, Engineering and Mathematics, International University Malaya-Wales, Jalan Tun Ismail, 50480, Kuala Lumpur, Malaysia

8) Central, South Carolina, USA

9) School of Geography and Oceanography, Nanjing University, Nanjing, China.

10) Forest Global Earth Observatory, Smithsonian Tropical Research Institute, Washington, DC, USA

11) Asian School of the Environment, Nanyang Technological University, Singapore, Singapore

12) School of Biological Sciences, The University of Queensland, St Lucia, Brisbane, QLD 4072, Australia

* Corresponding authors: f.q.brearley@mmu.ac.uk (FQB), foundinkualalumpur@yahoo.com (JMA), mattluskin@gmail.com (MSL)

\section{ACKNOWLEDGEMENTS}

We acknowledge the grant provided by Universiti Kebangsaan Malaysia for molecular work (M1-2018-004). We thank the Forest Research Institute of Malaysia (FRIM), the Negeri Sembilan Forestry Department and the Pasoh Research Committee for maintaining the Pasoh Forest and for research permission. We acknowledge ForestGEO of the Smithsonian Tropical Research Institute and FRIM for maintaining and supporting the Pasoh 50-ha forest dynamics plot and assistance funding for the exclosure experiment. We thank XX anonymous reviewers for useful comments on earlier drafts. 


\section{Wild pigs mediate far-reaching agricultural impacts 44 on tropical forest soil microbial communities}

\section{ABSTRACT}

Edge effects, the altered abiotic and biotic conditions on the borders of natural areas, rarely extend more than a few hundred meters. Edge effects have rarely been linked to altered soil biota, which shape ecosystem processes including carbon storage, biogeochemical cycling, and plant performance. Here, we investigated if agriculturally-mediated increased wildlife populations affect soil biotic communities at a distance well over that of estimated edge effects when they move between agriculture and natural habitats using a 22-year fenced exclusion experiment in a primary rainforest in Peninsular Malaysia. We found that the presence of wildlife (mainly native pigs (Sus scrofa) that crop-raid in nearby oil palm plantations) was associated with higher bacterial diversity, and an altered community composition (mediated by changes in soil $\mathrm{pH}$ ), and reduced abundances of symbiotic ectomycorrhizal fungi compared to soil in exclosures. There were only minor effects of pigs on soil chemistry or microclimate, so we suggest that changes in soil communities are driven by pigs' leaf litter removal and alterations to plant composition. Our study highlights that indirect effects from agriculture can be transferred by wildlife $>1 \mathrm{~km}$ into protected areas and this could have important repercussions for ecosystem processes and plant-soil feedbacks.

\section{INTRODUCTION}

Agricultural encroachment into forested areas is a pervasive global phenomenon that has a clear and direct impact on above- $(1,2)$ and below-ground (3) biota and ecosystem processes, especially in tropical forests. It is more challenging to assess how agricultural expansion indirectly affects natural areas over larger spatial scales, such as the cryptic degradation from edge effects. One example is cross-boundary ecological cascades, wherein adjacent ecosystems - first appearing to be distinct - are actually linked through the transport of nutrients (e.g. via floods or mobile animals) or interactions with wildlife that moves across ecotones (4). With over $70 \%$ of remaining forests now lying within $1 \mathrm{~km}$ of an edge (5), there is an urgent need to understand how edge effects reshape the linkages between above- and below-ground biota and the scale at which they operate.

Wildlife responses to edges are related to their unique habitat preferences, the local hunting intensity and preferences, and some crop-raiding wildlife can even benefit from supplemental foraging in nearby farmlands (4,6-9). Edge effects also produce a range of impacts on soils that are often mediated by microclimate and light (10), as well as plant species composition (e.g. 11-13). However, these edge effects have rarely been documented beyond a few hundred meters $(10,14,15)$. Wildlife plays an important role moderating nutrients like nitrogen and phosphorus, and soil biota through deposition of excrement and carcases (16-19). Wildlife also 
80 affects soil physical environments through biopedoturbation (20-22) and plant-soil interactions

81 via herbivory or nest building (23-26).

83 Here, we investigate the potential for wide-ranging wildlife to transfer far-reaching edge effects

84 on soil microbial communities in distant 'interior' primary forests at distances $>1 \mathrm{~km}$ from the

85 nearest edges. We conducted our study in a primary Malaysian rainforest where native forest-

86 dwelling wild boars (Sus scrofa) that forage in nearby oil palm plantations (Elaeis guineensis)

87 have elevated densities and are known to disturb nearby forest soils and plant communities

$88(4,27,28)$. Wild boars (hereafter 'pigs') are a key example of a broadly distributed generalist

89 vertebrate that is adaptable to human environments (e.g. forest edges) and strongly affected

90 by humans via hunting (negative) or crop-raiding (positive). Pigs are considered an 'ecosystem

91 engineer' due to the major physical soil disturbances via rooting, grubbing (predating larger soil

92 invertebrates), wallowing, trampling and soil compaction (29-30).

94 We focus on pigs' influence on microbial community composition and functioning, which remains 95 largely unknown and has myriad links to biogeochemical processes that in turn shape ecosystem properties including carbon dynamics (31). Using a long-term exclosure experiment, we examined three hypotheses regarding the indirect impacts from oil palm-fed pigs on the forest soil microbial communities based on the ecology of pigs and known relationships between soil disturbances and microbial communities:

1) First, we predicted that pig-exposed soils would have greater nutrient concentrations due the deposition of urine and faeces and that, together with disturbances caused by removal of understorey plants and leaf litter by pigs, these would be key drivers of microbial community structure in pig-exposed soils.

2) Second, we predicted that soil bacteria would be more impacted than fungi due to changes in nitrogen deposition from excrement influencing bacteria involved in the nitrogen cycle, and removal of understorey plants and leaf litter, which increases light penetration and likely has a drying effect on soils to which bacteria are more sensitive than fungi (32).

3) Third, we predicted that whilst fungi would be less influences by the presence of pigs than bacteria, symbiotic ectomycorrhizal (EcM) fungi would be reduced in pigexposed soils because pigs preferentially remove dipterocarp seedlings (23) that are associated with these fungi.

115 There were low concentrations of all soil nutrients measured, which is typical for Southeast 116 Asian rain forests on similar substrates (Table S1). There were no significant differences 
117 between the exclosures and the open-control areas with the exception of soil $\mathrm{pH}$ that was 0.15

$118 \mathrm{pH}$ units more acidic within the exclosures.

Bacterial richness was $13 \%$ lower in exclosure soils (t-test, $\mathrm{P}=0.042 ; \mathrm{Fig} 1 \mathrm{a}$ ). The relative abundance of Acidobacteria increased ( $t$ test, $P=0.013$; Fig $2 a$ ) but there was lower relative abundance of Proteobacteria, Actinobacteria, Planctomycetes and Gemmatimonadetes (all P < 0.05; Fig. 2). At the subphylum level, we also observed significant differences in the relative abundance of dominant bacterial taxa, for example, the relative abundance of bacterial families

125 Solibacteraceae and Rhabdochlamydiaceae increased, whilst abundance of other families such 126 as Bradyrhizobiaceae and Xanthomonadaceae, including members with biological $\mathrm{N}_{2}$-fixation capacities, declined in exclosure soils (Table S2). The bacterial community composition differed between the exclosures and the open-controls (ANOSIM $R=0.216, p 0.009$; Figs $2 \& 3 a$ ) and was influenced by soil pH (Fig. 3a). Soil carbon and potassium also influenced the bacterial community composition, but these did not differ between the exclosure and open-control soils (Table S1). There was no clear influence of the exclosures on bacterial community functioning as measured by predicted gene abundance (ANOSIM $R=0.081, p=0.23$; Fig $3 c$ ).

(a) Bacterial diversity

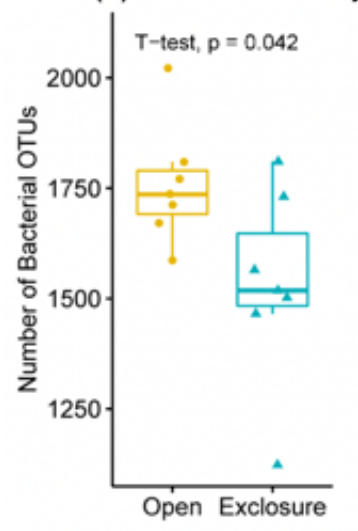

(b) Fungal diversity

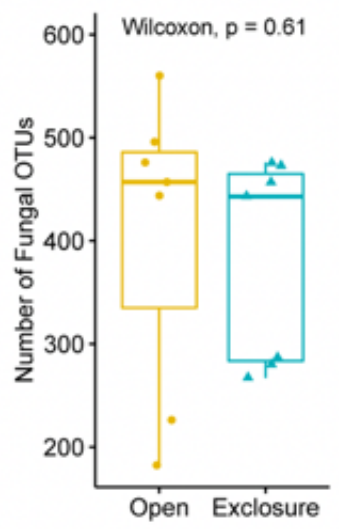

(c) EcM diversity

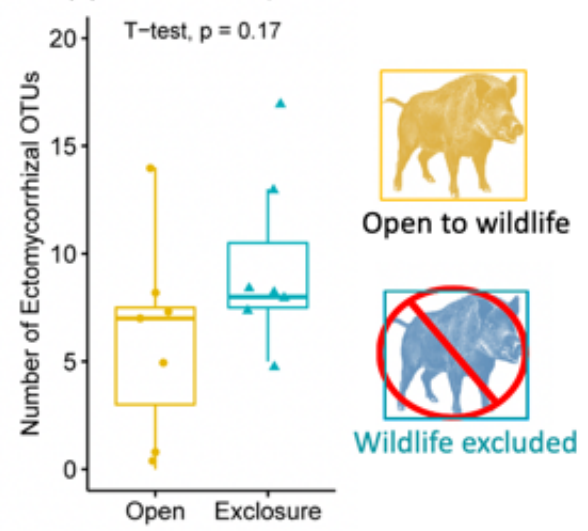

Figure 1: The long-term effects of wildlife (primarily pigs) on soil microbial diversity at Pasoh Forest Reserve in Peninsular Malaysia. Samples are separated by whether they were taken from open-control plots where there were many pigs (yellow dots) versus within fenced exclosures without pigs (blue triangles). EcM = Ectomycorrhizal fungi. 
(a)

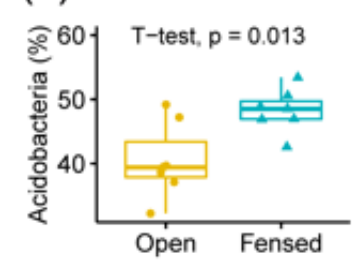

(e)

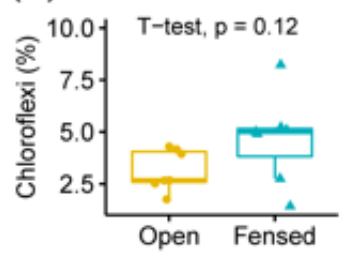

(i)

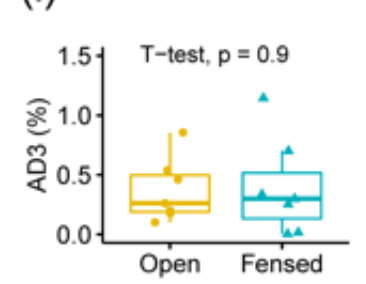

(b)

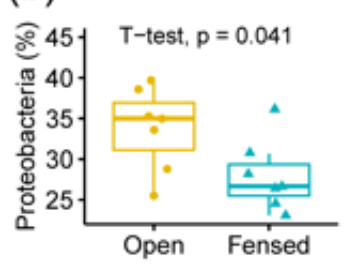

(f)

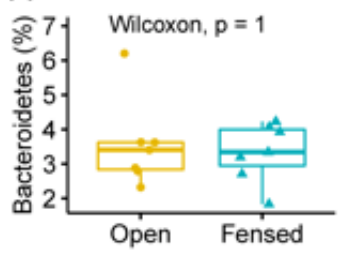

(c)

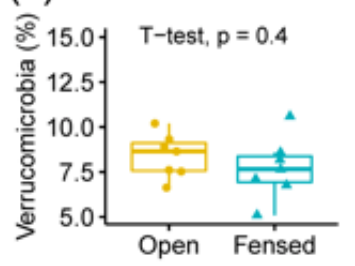

(g)

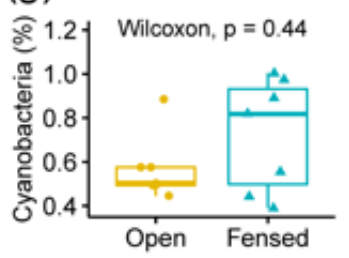

(d)

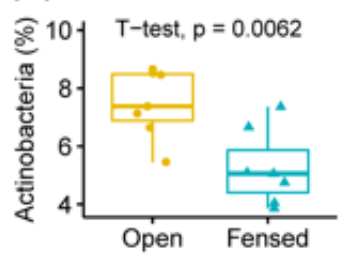

(h)

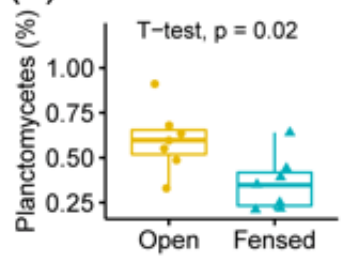

141
Figure 2: Influence of wildlife (primarily pigs) on the relative abundance of soil bacterial phyla at Pasoh Forest Reserve in Peninsular Malaysia (interpretation is the same as Fig. 1).

(j)

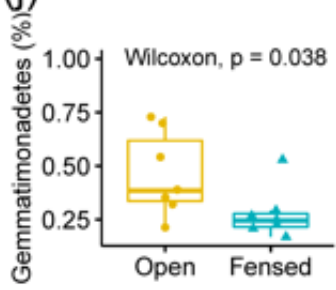

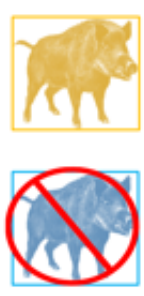

Open to pigs

Pigs exclued

The fungal community did not differ significantly between the exclosure and open-control soils in terms of diversity (Wilcoxon test, $\mathrm{P}=0.61$; Fig $1 \mathrm{~b}$ ), phylum abundance (Wilcoxon test, all $\mathrm{P}>$ 0.05; Fig S1), community composition (ANOSIM: $\mathrm{R}=-0.043, \mathrm{p}=0.70$; Fig $3 \mathrm{~b}$ ) or guild composition (Fig. S2). However, the ectomycorrhizal (EcM) fungal community composition differed between wildlife treatments (ANOSIM $p=0.03$; Fig 3d), becoming 1.3 times more diverse (t-test, $\mathrm{P}=0.17$; Fig. $1 \mathrm{C}$ ) and 2.9 times more abundant in exclosure soils (Wilcoxon test, $\mathrm{P}=0.16$; Fig. S2b). In particular, although the abundance of the most common EcM family Russulaceae was variable it was, overall, 2.5 times more abundant in the exclosure soils (Wilcoxon test, $\mathrm{P}=0.38$ ). The fungal community composition (including all species) was influenced by soil carbon (Fig. 3b) but none of the soil chemical variables significantly influenced the EcM community structure.

\section{DISCUSSION}

Our study is the first to link agricultural incursions to altered soil microbial community composition in adjacent habitats at distances $>1 \mathrm{~km}$ from edges, one of the furthest soil-related edge effects yet recorded. These far-reaching edge effects were mediated by crop-raiding native 
pigs that fed on oil palm fruits in adjacent plantations and then return to forests. The bioticallydriven impacts by pigs that we report are distinct from more well-documented edge effects related to habitat and abiotic conditions, since all our sampling locations were equidistant from edges and microclimatic differences were not detected greater than $100 \mathrm{~m}$ from the edge at our site (33). Instead, we posit that pigs impact soil microbial communities by disturbing soils, leaf litter, and understory vegetation and altering the plant community composition $(4,23,34)$. For example, previous work at our site has shown pigs reduce trees with symbiotic root-associated ectomycorrhizal (ECM) fungi (e.g. Dipterocarpaceae) and facilitate lianas that are rarely reported to have EcM associations (35). As predicted, we found wildlife exclusion was associated with altered ECM fungi communities and a greater relative abundance of ECM fungi. Wildlife exclusion was also associated with reduced soil bacterial diversity which led to a greater community change than for the fungal community. Prior work has found invasive pigs reduced soil bacterial diversity in Hawaii (36) - the opposite trend we observed from native pigs - and, in New Zealand, invasive pig grubbing may increase the relative abundance of fungi over bacteria (37) which our results supported.

(a)

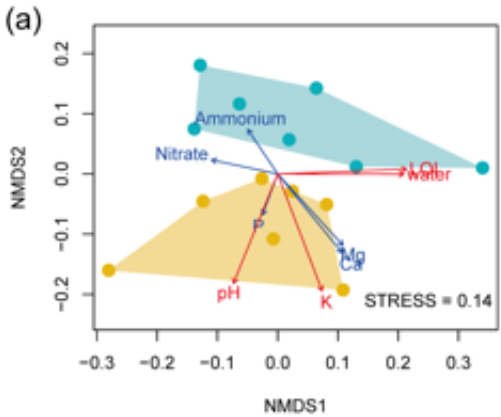

(c)

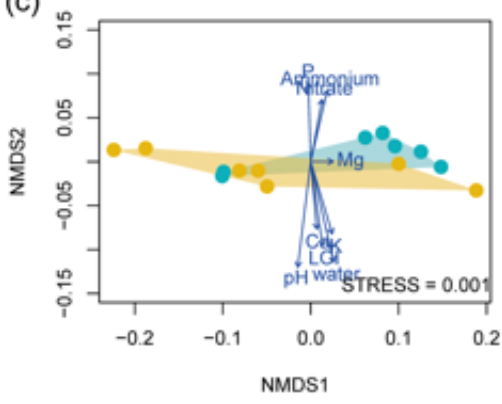

(b)

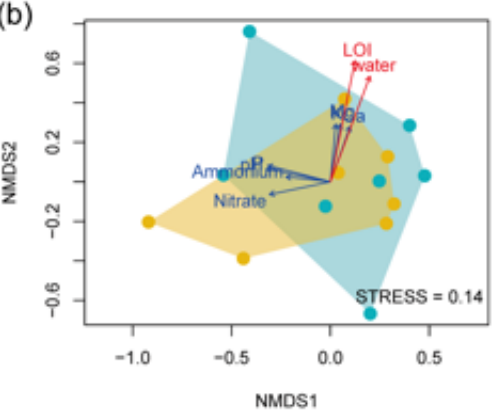

(d)

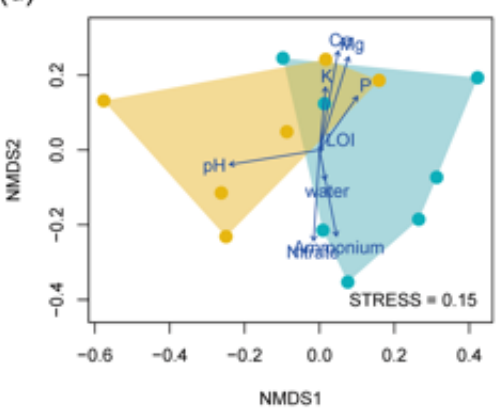

Figure 3: NMDS ordinations showing the influence of wildlife (primarily pigs) on the soil microbial community composition and function at Pasoh Forest Reserve in Peninsular Malaysia. (a) Bacterial taxa (b) Fungal taxa (c) Bacterial gene abundance (d) Ectomycorrhizal fungal taxa. Samples are separated by whether they were taken from open-control plots where there were many pigs (yellow dots) versus within fenced exclosures without pigs (blue triangles). Environmental factors that have a significant influence are marked in red. LOI = loss-on-ignition (\%). 
188 We did not detect higher soil nutrient concentrations due to pig excrement (urine and faeces) 189 deposition in open-control plots as we had predicted. Such equivocal results align with work 190 finding a wide variety of impacts from wildlife on soil nutrients $(17,38,39)$. It is also possible 191 that additional nutrients from wildlife excrement could have been balanced with loss from leaf 192 litter removal. Soil $\mathrm{pH}$ was slightly $(0.15 \mathrm{pH}$ units) more acidic in exclosure soils but - as has 193 previously been noted by others $(40,41)$ - this was associated with altered bacterial community 194 composition. As predicted, we found varying trends in relative abundance of bacterial taxa, for 195 example, the family Solibacteraceae (phylum Acidobacteria) dominated in exclosure soils, while 196 the family Vicinamibacteraceae (phylum Acidobacteria) was abundant in open-control soils. The relative abundance of Solibacteraceae is reported to decline with increasing soil $\mathrm{pH}(42)$ and organic fertilization (e.g. manure) (43), while that of Vicinamibacteraceae is positively correlated with $\mathrm{pH}(42)$ and had a higher prevalence in nutrient-amended soils (44). Contrary to our prediction, the relative abundance of bacterial families such as Bradyrhizobiaceae and Xanthomonadaceae, which include members with biological $\mathrm{N}_{2}$-fixation capacities, increased in open-control soils. However, $\mathrm{N}_{2}$-fixing members of these families are also known for their denitrifying abilities (45), which suggest that nitrogen deposition from urine and faeces from the pigs could have increased their abundance together with other denitrifying bacterial taxa such as in Rhodospirillaceae (46). Furthermore, in accordance with our prediction, we found a dominance of drought-tolerant Actinobacterial taxa $(47,48)$ in open-control soils.

208 We had predicted soil nutrients, water, and soil carbon, which are associated with the energy available for micro-organisms, would drive differences in soil microbial communities. However, while we found that bacterial community composition was associated with soil carbon and potassium, these attributes did not differ between exclosures and open-control soils suggesting these factors did not explain differences in bacterial communities between exclosure treatments. Instead, bacterial community change was more likely associated with abiotic conditions, including leaf litter removal and increased light penetration from a browsed and trampled understory vegetation that may cause increased light penetration and soil drying. treatments, and open-control soils were associated with lower relative abundance and diversity of EcM fungi, although there was borderline statistical significance due to only having seven replicates and the potential to improve fungal guild assignment via FUNGuild (49). Pigs may directly consume some fungi or, more likely, the disproportionate removal of trees with symbiotic relationships with EcM fungi (23) is key here. The decline in EcM fungi may cause plant-soil feedbacks that reduce regeneration of EcM-dependent plant species such as dipterocarps (50) and therefore influence future patterns of forest composition. Future work testing if EcM fungi and their plant symbionts differ in unhunted forests with abundant pigs (e.g. 
Pasoh) compared to hunted forests were pigs are rare, such as in Lambir Hills in Malaysian Borneo (51) would be of great interest.

In summary, our study is notable for documenting that cryptic biotically-driven edge effects are mediated by wide-ranging wildlife and affect soil microbial community composition. The magnitude of impacts we observed at our site is linked to elevated pig populations associated with oil palm plantations and low hunting pressure(4), thereby creating a cross-boundary ecological cascade from agriculture to pig to soils that extends $>1 \mathrm{~km}$. Pigs are common throughout Asia and invasive globally $(29,30,52,53)$, so our findings may be generalizable beyond Malaysia, and to other mobile crop-raiding wildlife species besides pigs $(7,54)$. The onslaught of African Swine Fever in Asia, which has spread to wild pigs, may reduce pigs' abundance, and provide opportunities for natural experiments on the ecological impacts of losing pigs (55). Other future research may examine associations between soils and volant animals that are often wider ranging, and examine feedback loops between altered soils and plant composition. We conclude with a warning that far-reaching edge effects may produce consequential changes to ecosystem properties and processes performed by soil microbes, as well as alter plant performance and community composition in the future.

\section{METHODS}

\section{Study site}

246 The study was conducted at the Pasoh Forest Reserve, Negeri Sembilan, Peninsular Malaysia $247\left(2^{\circ} 59^{\prime} \mathrm{N}, 102^{\circ} 18^{\prime} \mathrm{E}\right)$ where the mean annual precipitation is approximately $1800 \sqsupset \mathrm{mm}$ (56). In 248 the study area, the soils are developed over shale, granite and alluvial parent materials with a generally gentle topography and a fairly homogenous vegetation composition (56). The lowland evergreen rain forest core of the reserve is a 600 ha tract dominated by Dipterocarpaceae and typical of much of the broader region (56). Oil palm plantations surround the reserve on three sides (extending for 2 to $10 \mathrm{~km}$ away from the reserve) with the northern side abutting a contiguous area of selectively logged lowland and hill forest. Pasoh supports a diverse wildlife community (4) but pigs (Sus scrofa) are by far the most common mammal and present at very high densities of 27-47 per $\mathrm{km}^{2}(4,52)$. Pigs are known to cause soil disturbances in the forest

\section{Wildlife exclosure experiment}

258 Eight open-topped exclosures were constructed in 1996 along the southern edge of the 50-ha permanent Forest Dynamics Plot, and $1.3 \mathrm{~km}$ from the nearest forest edge (57). The exclosures were $7 \mathrm{~m} \times 7 \mathrm{~m}$, with $1.5 \mathrm{~m}$ tall fences made from $4-\mathrm{cm}^{2}$ chain-link metal and surrounded by

261 barbed wire. Each fenced area was paired with two adjacent open-control areas located at least

$2621 \mathrm{~m}$ outside the fences. At the time of this study, seven remained effective and one was 
263 damaged by falling trees and was not surveyed. Exclosures are described in more detail by

264 Ickes et al. (34) and Luskin et al. (57).

265 Soil sampling and DNA extraction

266 Surface soil (0-5 cm depth) samples were collected in July 2018 from the seven exclosures and

267 seven of their paired controls. We took soils from four points at the corners of a $1 \times 1 \mathrm{~m}^{2}$ grid

268 and composited them for further analysis. We avoided sampling areas in the controls that had

269 been grubbed by pigs, as this would have exposed sub-surface soil that is known to have a

270 different microbial community to the upper horizons. Soils were kept chilled for c. 48 hours

271 before DNA was extracted from $0.25 \mathrm{~g}$ of each soil sample using a MoBio PowerSoil kit following

272 the manufacturer's instructions.

273 DNA sequencing

274 Extracted soil DNA was PCR-amplified in duplicate using the high-fidelity Phusion polymerase. A

275 single round of PCR was done using "fusion primers" (Illumina adaptors + indices + specific

276 regions) targeting the V6-V8 region of $16 \mathrm{~S}$ rRNA gene of bacteria and the internal transcribed

277 spacer (ITS) 2 region of fungi using the B969F \& BA1406R primers of Comeau et al. (58) and

278 ITS86(F) \& ITS4(R) primers of Op De Beeck (59) respectively. The PCR products were cleaned

279 and normalized using the high-throughput Charm Biotech Just-a-Plate 96-well Normalization Kit

280 and pooled to make one library that was quantified fluorometrically before sequencing.

281 Sequencing library construction and Illumina MiSeq sequencing ( $2 \times 300 \mathrm{bp}$ ) were performed at

282 the Integrated Microbiome Resource, Dalhousie University, Canada (https://imr.bio/index.html).

283 Bioinformatics

284 Forward and reverse sequences were assembled using PANDAseq v.2.8 and further sequence 285 processing was performed following the MiSeq SOP in Mothur v.1.32.1 with chimeric sequences 286 removed using chimera.uchime (60-62). Operational taxonomic units (OTUs) of bacterial 165 287 rRNA gene sequences were assigned based on the OptiClust algorithm using Mothur v.1.40.5 288 with a $97 \%$ similarity threshold and OTUs of fungal ITS sequences were assigned based on the 289 UCLUST algorithm using QIIME v.1.9.1 with a $97 \%$ similarity threshold $(63,64)$. Singleton 290 sequences were removed. Bacterial sequences were then classified based on EzBioCloud 291 database v.2018.05 for bacteria (65) and the UNITE database v.7.2 for fungi (66). To infer the

292 bacterial functions from 16S rRNA gene sequences, we used Phylogenetic Investigation of 293 Communities by Reconstruction of Unobserved States (PICRUSt v. 1.1.2 (67). PICRUSt uses 294 extended ancestral-state reconstruction algorithm to generate the composition of gene families 295 for the subset of OTUs present in Greengenes database v. 13.5 (68). The predicted gene 296 families were then classified into Kyoto Encyclopedia of Genes and Genomes (KEGG) 297 orthologues (69). We used FUNGuild v.1.0 for functional guild classification of fungi (49).

\section{Soil analyses}

299 In the field, c. $2.5 \mathrm{~g}$ fresh soil was added to $20 \mathrm{ml}$ of $1 \mathrm{M} \mathrm{KCl}$, shaken and returned to the field 300 laboratory where it was filtered through a $0.2 \mu \mathrm{m}$ filter after c. 6 hours. It was then diluted 1:4 
and analysed on a Dionex ICS 6000 ion chromatograph for available ammonium and nitrate. The moisture content of fresh soil was determined by heating subsamples to $105^{\circ} \mathrm{C}$ for $24 \mathrm{~h}$ and the remainder was air-dried and ground to pass a $1-\mathrm{mm}$ sieve. Soil $\mathrm{pH}$ was measured by adding $2.5 \mathrm{~g}$ of soil to $6.25 \mathrm{ml}$ of deionised water; the mixture was then shaken and left to equilibrate for $24 \mathrm{~h}$ before measurement with a Sartorius PB-11 pH meter. Total carbon and nitrogen were determined on a Vario EL Cube elemental analyser. Cations ( $\mathrm{P}, \mathrm{K}, \mathrm{Ca}$ and $\mathrm{Mg}$ ) were extracted from $2.5 \mathrm{~g}$ sub-samples that were shaken with $25 \mathrm{ml}$ of Mehlich 3 solution for ten minutes before being filtered and analysed on a Thermo iCAP 6300 Duo inductively coupled plasma optical emission spectrometer with correction by determining moisture content of the air-dried soil by heating subsamples as above.

312 For diversity analysis, bacterial sequences were subsampled into 23,601 reads and fungal sequences were subsampled into 8,994 reads. To compare relative abundance of phyla and diversity between treatments we used t-tests when data were normally distributed or Wilcoxon rank sum tests when data were not normally distributed. We used Bray-Curtis dissimilarity (based on square-root transformed abundances) to visualize differences in the bacterial and fungal communities between treatments and the KEGG Level 3 gene assignments (69). We drew NMDS (non-metric multidimensional scaling) plots using the 'metaMDS' function in $R$ package 'vegan' (70). Statistical significance between treatments were tested by Analysis of Similarities test (ANOSIM). We assessed if microbial composition was influenced by abiotic conditions by including environmental vectors (covariates) in the NMDS ordinations using the vegan 'envfit' function'.

\section{LITERATURE CITED}

1. Gibbs, H. K. et al. 2010. Tropical forests were the primary sources of new agricultural land in the 1980s and 1990s. - Proceedings of the National Academy of Sciences of the USA 107: 1673216737.

2. Gibson, L. et al. 2011. Primary forests are irreplaceable for sustaining tropical biodiversity. Nature 478: 378-381.

3. Brearley, F. Q. and Thomas, A. D. 2015. Land-use Change Impacts on Soil Processes: Tropical and Savannah Ecosystems. - CABI, Wallingford, UK.

4. Luskin, M. S. et al. 2017. Cross-boundary subsidy cascades from oil palm degrade distant tropical forests. - Nature Communications 8: 2231.

5. Haddad, N. M. et al. 2015. Habitat fragmentation and its lasting impact on Earth's ecosystems. Science Advances 1: e1500052.

6. Yahner, R. H. 1988. Changes in wildlife communities near edges. - Conservation Biology 2: 333339.

7. Rand, T. A. et al. 2006. Spillover edge effects: the dispersal of agriculturally subsidized insect natural enemies into adjacent natural habitats. - Ecology Letters 9: 603-614. 
8. Prugh, L. R. et al. 2008. Effect of habitat area and isolation on fragmented animal populations. Proceedings of the National Academy of Sciences of the USA 105: 20770-20775.

9. Pfeifer, M. et al. 2017. Creation of forest edges has a global impact on forest vertebrates. - Nature 551: $187-191$.

10. Murcia, C. 1995. Edge effects in fragmented forests: implications for conservation. - Trends in Ecology \& Evolution 10: 58-62.

11. Flores-Rentería, D. et al. 2015. Habitat fragmentation can modulate drought effects on the plantsoil-microbial system in Mediterranean holm oak (Quercus ilex) forests. - Microbial Ecology 69: 798-812.

12. Flores-Rentería, D. et al. 2016. Agricultural matrix affects differently the alpha and beta structural and functional diversity of soil microbial communities in a fragmented Mediterranean holm oak forest. - Soil Biology and Biochemistry 92: 79-90.

13. Forbes, E. S. et al. 2019. Synthesizing the effects of large, wild herbivore exclusion on ecosystem function. - Functional Ecology 33: 1597-1610.

14. Laurance, W. F. 2000. Do edge effects occur over large spatial scales? - Trends in Ecology \& Evolution 15: 134-135.

15. Ewers, R. M. and Banks-Leite, C. 2013. Fragmentation impairs the microclimate buffering effect of tropical forests. - PLoS One 8: e58093.

16. Wardle, D. A. et al. 2004. Ecological linkages between aboveground and belowground biota. Science 304: 1629-1633.

17. Bueno, C. G. et al. 2013. Occurrence and intensity of wild boar disturbances, effects on the physical and chemical soil properties of alpine grasslands. - Plant and Soil 373: 243-256.

18. Brodie, J. F. and McIntyre, P. B. 2019. Bushmeat biogeochemistry: hunting tropical mammals alters ecosystem phosphorus budgets. - Proceedings of the Royal Society B 286: 20190966.

19. Villar, N. et al. 2021. Frugivory underpins the nitrogen cycle. - Functional Ecology 35: 357-368.

20. Rosin, C. et al. 2017. A pantropical assessment of vertebrate physical damage to forest seedlings and the effects of defaunation. - Global Ecology and Conservation 11: 188-195.

21. Lamperty, T. et al. 2020. Defaunation of large mammals alters understory vegetation and functional importance of invertebrates in an Afrotropical forest. - Biological Conservation 241: 108329.

22. Tuomi, M. et al 2021. Stomping in silence: Conceptualizing trampling effects on soils in polar tundra. - Functional Ecology 35: 306-317.

23. Ickes, K. et al. 2005. Impacts of nest construction by native pigs (Sus scrofa) on lowland Malaysian rain forest saplings. - Ecology $86: 1540-1547$.

24. Wirth, R. et al. 2008. Plant herbivore interactions at the forest edge. - In: Progress in Botany (eds. U Lüttge et al.). Springer, Berlin, Germany, pp. 423-448.

25. Porensky, L. M. 2011. When edges meet: interacting edge effects in an African savanna. - Journal of Ecology 99: 923-934.

26. Andriuzzi, W. S. and Wall, D. H. 2017. Responses of belowground communities to large aboveground herbivores: Meta-analysis reveals biome-dependent patterns and critical research gaps. - Global Change Biology 23: 3857-3868. 
27. Fujinuma, J. and Harrison, R. D. 2012. Wild pigs (Sus scrofa) mediate large-scale edge effects in a lowland tropical rainforest in Peninsular Malaysia. - PloS One 7: e37321.

28. Luskin, M. S. et al. 2021. Wildlife disturbances as a source of conspecific negative densitydependent mortality in tropical trees. - Proceedings of the Royal Society B 288, 1946-1956.

29. Barrios-Garcia, M. N. and Ballari, S. A. 2012. Impact of wild boar (Sus scrofa) in its introduced and native range: a review. - Biological Invasions 14: 2283-2300.

30. Bevins, S. N. et al. 2014. Consequences associated with the recent range expansion of nonnative feral swine. - BioScience 64: 291-299.

31. Cavicchioli, R. et al. 2019. Scientists' warning to humanity: microorganisms and climate change. Nature Reviews Microbiology 17: 569-586.

32. de Vries, F. T. et al. 2018. Soil bacterial networks are less stable under drought than fungal networks. - Nature Communications 9: 3033.

33. Luskin, M. S. and Potts, M. D. 2011. Microclimate and habitat heterogeneity through the oil palm lifecycle. - Basic and Applied Ecology 12: 540-551.

34. Ickes, K. et al. 2001. Effects of native pigs (Sus scrofa) on woody understorey vegetation in a Malaysian lowland rain forest. - Journal of Tropical Ecology 17: 191-206.

35. McGuire, K. L. et al. (2008) Dual mycorrhizal colonization of forest-dominating tropical trees and the mycorrhizal status of non-dominant tree and liana species. - Mycorrhiza 18: 217-222.

36. Wehr, N. H. et al. 2019. Changes in soil bacterial community diversity following the removal of invasive feral pigs from a Hawaiian tropical montane wet forest. - Scientific Reports 9: 14681.

37. Parkes, J. P. et al. 2015. Causes and consequences of ground disturbance by feral pigs (Sus scrofa) in a lowland New Zealand conifer-angiosperm forest. - New Zealand Journal of Ecology 39: $34-42$.

38. Singer, F. J. et al. 1984. Effects of wild pig rooting in a deciduous forest. - The Journal of Wildlife Management: $464-473$.

39. Bruinderink, G. G. and Hazebroek, E. 1996. Wild boar (Sus scrofa scrofa L.) rooting and forest regeneration on podzolic soils in the Netherlands. - Forest Ecology and Management 88: 71-80.

40. Fierer, N. and Jackson, R. B. 2006. The diversity and biogeography of soil bacterial communities. Proceedings of the National Academy of Sciences of the USA 103: 626-631.

41. Tripathi, B. M. et al. 2012. Tropical soil bacterial communities in Malaysia: pH dominates in the equatorial tropics too. - Microbial Ecology 64: 474-484.

42. Jones, R. et al. 2009. A comprehensive survey of soil acidobacterial diversity using pyrosequencing and clone library analyses. - ISME Journal 3: 442-453.

43. Soman, C. et al. 2017. Long-term fertilizer and crop-rotation treatments differentially affect soil bacterial community structure. - Plant and Soil 413: 145-159.

44. Van der Bom, F. et al. 2018. Long-term fertilisation form, level and duration affect the diversity, structure and functioning of soil microbial communities in the field. - Soil Biology and Biochemistry 122: 91-103.

45. Shapleigh, J. P. 2013. Denitrifying prokaryotes. In: The Prokaryotes: Prokaryotic Physiology and Biochemistry (eds. E. Rosenberg et al.). Springer, Berlin, Germany, pp. 405-425.

46. Satoh, T. et al. 1976. Rhodopseudomonas sphaeroides forma sp. denitrificans, a denitrifying strain as a subspecies of Rhodopseudomonas sphaeroides. Archives of Microbiology, 108: 265-269. 
47. Barnard, R. et al. 2013. Responses of soil bacterial and fungal communities to extreme desiccation and rewetting. - ISME Journal 7: 2229-2241.

48. Bouskill, N. et al. 2013. Pre-exposure to drought increases the resistance of tropical forest soil bacterial communities to extended drought. ISME Journal 7: 384-394.

49. Nguyen, N. H. et al. 2016. FUNGuild: an open annotation tool for parsing fungal community datasets by ecological guild. - Fungal Ecology 20: 241-248.

50. Brearley, F. Q. 2012. Ectomycorrhizal associations of the Dipterocarpaceae. - Biotropica 44: 637648.

51. Harrison, R. D. et al. 2013. Consequences of defaunation for a tropical tree community. - Ecology Letters 16: 687-694.

52. Ickes, K. 2001. Hyper-abundance of native wild pigs (Sus scrofa) in a lowland dipterocarp rain forest of Peninsular Malaysia. - Biotropica 33: 682-690.

53. Ke, A. and Luskin, M. S. 2017. Integrating disparate occurrence reports to map data-poor species ranges and occupancy: a case study of the Vulnerable bearded pig Sus barbatus. - Oryx 53: 377387.

54. Oro, D. et al. 2013. Ecological and evolutionary implications of food subsidies from humans. Ecology Letters 16: 1501-1514.

55. Luskin, M. S. et al. 2021. African Swine Fever threatens Southeast Asia's 11 endemic wild pig species. - Conservation Letters: 12784 (in press).

56. Davies, S. J. et al. 2003. The trees of Pasoh Forest: stand structure and floristic composition of the 50-ha forest research plot. - In: Pasoh: Ecology of a Lowland Rain Forest in Southeast Asia (eds. T. Okuda et al.). Springer, Berlin, Germany, pp. 35-50.

57. Luskin, M. S. et al. 2019. Wildlife differentially affect tree and liana regeneration in a tropical forest: An 18-year study of experimental terrestrial defaunation versus artificially abundant herbivores. - Journal of Applied Ecology 56: 1379-1388.

58. Comeau, A. M. et al. 20110. Arctic Ocean microbial community structure before and after the 2007 record sea ice minimum. - PLoS One $6:$ e27492.

59. Op De Beeck, M. et al. (2014) Comparison and validation of some ITS primer pairs useful for fungal metabarcoding studies. - PLoS One 9: e97629.

60. Schloss, P. D. et al. 2009. Introducing mothur: open-source, platform-independent, communitysupported software for describing and comparing microbial communities. - Applied and Environmental Microbiology 75: 7537-7541.

61. Edgar, R. C. et al. 2011. UCHIME improves sensitivity and speed of chimera detection. Bioinformatics 27: 2194-2200.

62. Masella, A. P. et al. 2012. PANDAseq: paired-end assembler for illumina sequences. - BMC Bioinformatics 13: 31.

63. Edgar, R. C. 2010. Search and clustering orders of magnitude faster than BLAST. - Bioinformatics 26: 2460-2461.

64. Westcott, S. L. and Schloss, P. D. 2017. OptiClust, an improved method for assigning ampliconbased sequence data to operational taxonomic units. - Msphere 2: e00073-17.

65. Yoon, S.-H. et al. 2017. Introducing EzBioCloud: a taxonomically united database of $16 \mathrm{~S}$ rRNA gene sequences and whole-genome assemblies. - International Journal of Systematic and Evolutionary Microbiology 67: 16131617. 
66. Abarenkov, K. et al. 2010. The UNITE database for molecular identification of fungi-recent updates and future perspectives. - New Phytologist 186: 281-285.

67. Langille, M. G. et al. 2013. Predictive functional profiling of microbial communities using $16 \mathrm{~S}$ rRNA marker gene sequences. - Nature Biotechnology 31: 814-821.

68. DeSantis, T. Z. et al. 2006. Greengenes, a chimera-checked $16 \mathrm{~S}$ rRNA gene database and workbench compatible with ARB. - Applied and Environmental Microbiology 72: 5069-5072.

69. Kanehisa, M. et al. 2012. KEGG for integration and interpretation of large-scale molecular data sets. - Nucleic Acids Research 40: D109-D114.

70. Oksanen, J. et al. 2013. Package 'vegan.' - Community ecology package, version 2: https://CRAN.R-project.org/package=vegan. 


\section{Supplementary Materials}

479 Table S1: Soil chemical analysis (mean \pm standard error) within and outside exclosures to 480 prevent the influence of wildlife (primarily pigs) on ecological processes at Pasoh Forest Reserve 481 in Peninsular Malaysia.

\begin{tabular}{|l|l|l|l|}
\hline Soil Property & Exclosure & Open-Control & t-test \\
\hline $\mathrm{pH}$ & $4.03 \pm 0.02$ & $4.18 \pm 0.06$ & $\mathrm{t}=2.42, \mathrm{p}=0.032$ \\
\hline Loss-on-ignition $(\%)$ & $5.71 \pm 0.75$ & $5.29 \pm 0.69$ & $\mathrm{t}=0.42, \mathrm{p}=0.69$ \\
\hline $\mathrm{C}(\%)$ & $2.18 \pm 0.87$ & $2.15 \pm 0.73$ & $\mathrm{t}=0.05, \mathrm{p}=0.96$ \\
\hline $\mathrm{N}(\%)$ & $0.15 \pm 0.02$ & $0.14 \pm 0.02$ & $\mathrm{t}=0.30, \mathrm{p}=0.77$ \\
\hline Ammonium $\left(\mu \mathrm{g} \mathrm{g}^{-1}\right)$ & $6.08 \pm 10.90$ & $1.54 \pm 1.13$ & $\mathrm{t}=1.09, \mathrm{p}=0.30$ \\
\hline Nitrate $\left(\mu \mathrm{g} \mathrm{g}^{-1}\right)$ & $2.43 \pm 4.70$ & $2.63 \pm 4.80$ & $\mathrm{t}=0.08, \mathrm{p}=0.94$ \\
\hline Available $\mathrm{P}\left(\mu \mathrm{g} \mathrm{g}^{-1}\right)$ & $9.19 \pm 3.90$ & $9.58 \pm 3.92$ & $\mathrm{t}=0.18, \mathrm{p}=0.86$ \\
\hline Available $\mathrm{K}\left(\mu \mathrm{g} \mathrm{g}^{-1}\right)$ & $56.8 \pm 19.9$ & $79.7 \pm 43.6$ & $\mathrm{t}=1.27, \mathrm{p}=0.23$ \\
\hline Available $\mathrm{Ca}\left(\mu \mathrm{g} \mathrm{g}^{-1}\right)$ & $18.0 \pm 14.8$ & $25.9 \pm 16.3$ & $\mathrm{t}=0.94, \mathrm{p}=0.36$ \\
\hline Available $\mathrm{Mg}\left(\mu \mathrm{g} \mathrm{g}^{-1}\right)$ & $22.1 \pm 10.3$ & $26.0 \pm 9.9$ & $\mathrm{t}=0.74, \mathrm{p}=0.48$ \\
\hline
\end{tabular}


484 Table S2. Influence of wildlife (primarily pigs) on the relative abundance of the dominant 485 bacterial families within the phyla Acidobacteria, Actinobacteria, Chlamydiae and Proteobacteria 486 at Pasoh Forest Reserve in Peninsular Malaysia. Samples are separated by whether they were 487 taken from open-control plots where there were many pigs versus within fenced exclosures 488 without pigs. Only families for which significant differences were observed are shown.

\begin{tabular}{|l|l|l|}
\hline Taxa & Exclosure & Open-Control \\
\hline Acidobacteria & & \\
\hline Solibacteraceae & $8.69 \pm 1.16$ & $7.11 \pm 1.23$ \\
\hline Vicinamibacteraceae & $1.12 \pm 0.25$ & $1.89 \pm 0.35$ \\
\hline Actinobacteria & & \\
\hline Acidimicrobiaceae & $0.36 \pm 0.16$ & $0.52 \pm 0.08$ \\
\hline Conexibacteraceae & $0.37 \pm 0.14$ & $0.58 \pm 0.18$ \\
\hline Gaiellaceae & $0.11 \pm 0.08$ & $0.31 \pm 0.11$ \\
\hline Propionibacteriaceae & $0.04 \pm 0.04$ & $0.15 \pm 0.12$ \\
\hline Sphingobacteriaceae & $0.35 \pm 0.09$ & $0.58 \pm 0.15$ \\
\hline Streptomycetaceae & $0.42 \pm 0.25$ & $1.07 \pm 0.28$ \\
\hline Chlamydiae & & \\
\hline Rhabdochlamydiaceae & $0.17 \pm 0.07$ & $0.07 \pm 0.06$ \\
\hline Alphaproteobacteria & & \\
\hline Bradyrhizobiaceae & $3.21 \pm 0.63$ & $4.74 \pm 0.98$ \\
\hline Caulobacteraceae & $2.21 \pm 0.86$ & $4.04 \pm 1.97$ \\
\hline Micropepsaceae & $1.20 \pm 0.32$ & $1.75 \pm 0.22$ \\
\hline Rhodospirillaceae & $3.94 \pm 0.90$ & $5.08 \pm 0.76$ \\
\hline Deltaproteobacteria & & \\
\hline Polyangiaceae & $0.93 \pm 0.28$ & $1.73 \pm 0.72$ \\
\hline Gammaproteobacteria & & \\
\hline Steroidobacteraceae & $2.43 \pm 0.66$ & $3.34 \pm 0.55$ \\
\hline Xanthomonadaceae & $0.93 \pm 0.33$ & $1.33 \pm 0.93$ \\
\hline
\end{tabular}


491 Figure S1: Influence of wildlife (primarily pigs) on the relative abundance of soil fungal phyla at 492 Pasoh Forest Reserve in Peninsular Malaysia. Samples are separated by whether they were 493 taken from open-control plots where there were many pigs (yellow dots) versus within fenced 494 exclosures without pigs (blue triangles).

(a)

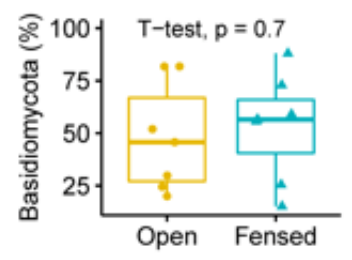

(e)

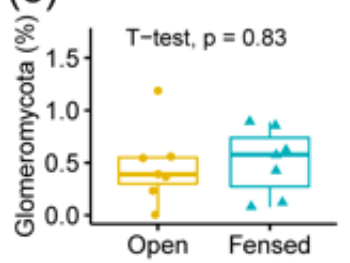

(b)

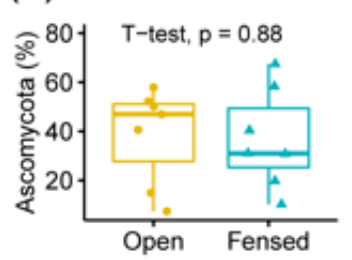

(f)

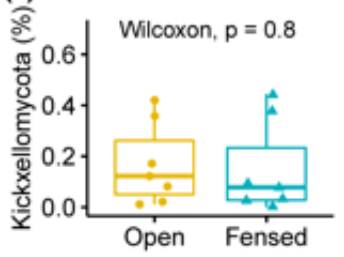

(c)

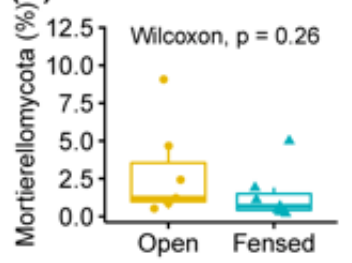

(g)

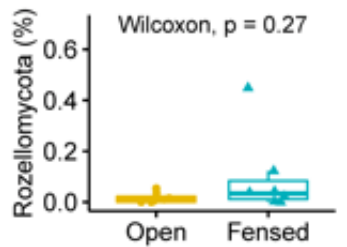

(d)

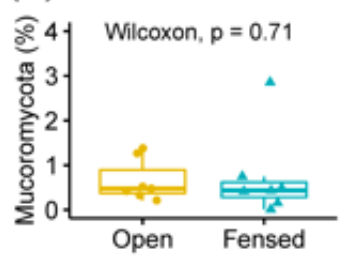

(h)

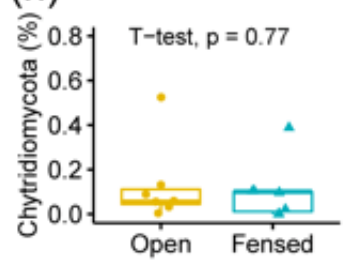

(i)

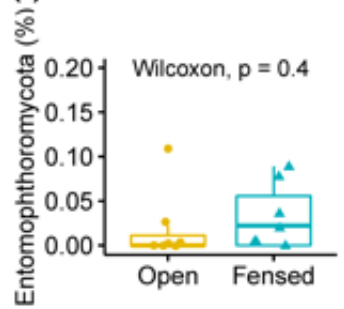

(j)

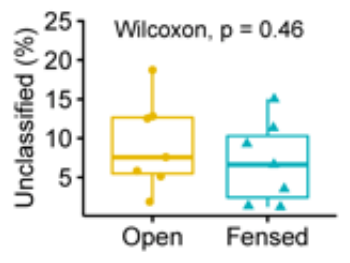


bioRxiv preprint doi: https://doi.org/10.1101/2021.09.10.459828; this version posted September 11,2021 . The copyright holder for this preprint (which was not certified by peer review) is the author/funder, who has granted bioRxiv a license to display the preprint in perpetuity. It is made available under aCC-BY-NC 4.0 International license.

497 Figure S2: Influence of wildlife (primarily pigs) on the relative abundance of soil fungal guilds $\mathrm{t}$ 498 Pasoh Forest Reserve in Peninsular Malaysia. (determined using FUNGuild) (interpretation same 499 as Fig S1).

(a)

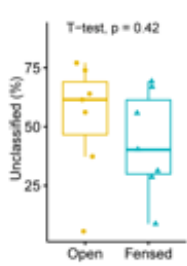

(g)

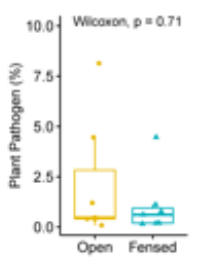

(b)

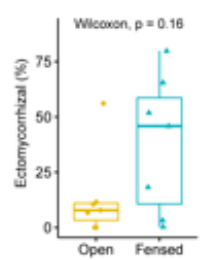

(h)

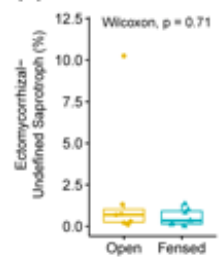

(c)

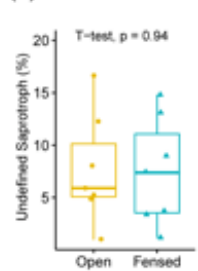

(i)

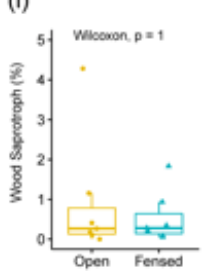

(d)
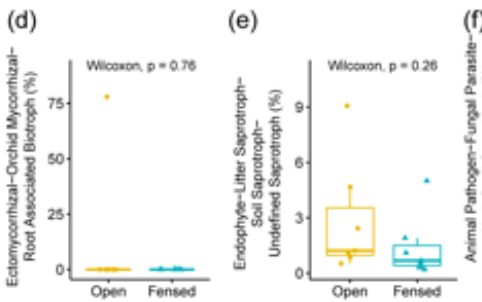

(j)

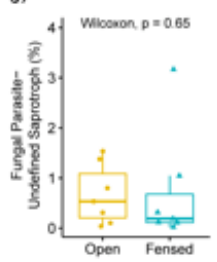

Open to pigs

Pigs exclued 